\title{
Structure Design and Optimization of the Repair Tower of 1000kV Overhead Transmission Lines
}

\author{
Hu Xiaoguang ${ }^{1, a}$, Han Junke ${ }^{1, b}$, Chen Cheng ${ }^{2, c}$, Li Qinghua ${ }^{1, d}$, Wang Fei , $^{1, e}$ \\ ${ }^{1}$ China Electric Power Research Institute, Xuanwu District, Beijing 100055, China \\ ${ }^{2}$ Zhejiang Electric Power Design Institute, Hangzhou 310012, China \\ adkyhxg@163.com, bhjk@epri.sgcc.com.cn, ${ }^{\mathrm{c}}$ rexcc@163.com, Iqh@epri.sgcc.com.cn, \\ e499422978@qq.com
}

Keywords: repair pole and tower; modularization; serialization; guyed tower

Abstract. Tower falling down or wire breaking caused by natural disasters is a serious threat to the safe operation of power transmission lines. To improve repair efficiency and quality of overhead transmission lines in the case of disasters and incidents, this paper designed a rapidly assembled pole and tower system, which is in light weight and is easy to be assembled, for $1000 \mathrm{kV} \mathrm{UHV}$ transmission lines. Moreover, it also put forward an optimization plan for structure of the repair tower. The calculation method and new structures specifically proposed by this project for $1000 \mathrm{kV}$ transmission lines can meet the needs of repair works of transmission lines of different voltage levels of cross-region power network, and they are of great significance to the construction of strong and smart power network..

\section{Introduction}

The repair tower is temporary rush-repair equipment, which can be rapidly installed to replace the damaged permanent tower. Usually bad weather or other natural disasters will make the transmission tower fall down, which spontaneously leads to power blackouts. Therefore, repair work is immediately required. The repair tower will be temporarily used to substitute the collapsed permanent tower so as to restore power as soon as possible. When repair works of the permanent tower are completed, wires will be transfered from the temporary repair tower to the new permanent tower, and the dismantled repair tower will be kept for next use. Since the repair tower is designed for emergency wrecking, it should be in a fine shape, a light weight and have a strong bearing capacity, and it should be able to reach the desired height only through a few guy wires and can carry large loads in different weather conditions. Thus, with a repair tower, a timely response of unexpected power failure can be made at that very instant, and corresponding losses can be minimized.

\section{Structure Form of the 1000kV Repair Tower}

The $1000 \mathrm{kV}$ UHV transmission line is now the highest voltage transmission line in the world. Its tower structure is very high and has a heavy load, and its tower components are large in size and heavy in weight. Moreover, falling down of those towers usually occurs in severe weather conditions in the mountainous areas where the terrain condition is poor, and transportation is difficult. In this case, if an accident of tower falling down happens, restore of the power line is very difficult to carry out. Based on requirements, such as reutilization, quick and efficient transportation and assembly of the repair tower, this paper designed a modularized guyed tower as the repair tower, which reduced the structural weight to the largest extent, and had an easy way to transport and assemble standard sections of the repair tower. The Schematic Diagram of the Repair Tower is shown in Fig.1(a) is the standard segment, which is installed according to requirements of tower height. Thanks to the standardized design, those segments can be connected end to end, without orderly assembly. The overall schematic is shown in Fig.1(b). 


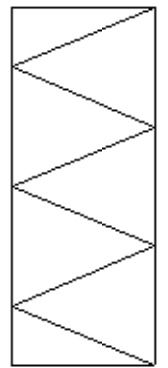

(a) Basic Module

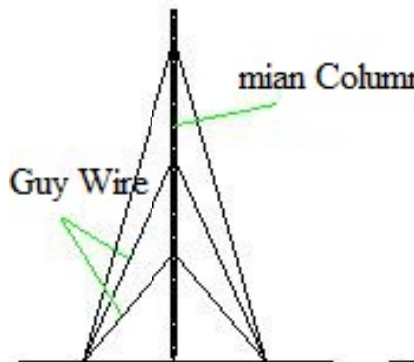

(b) The Overall

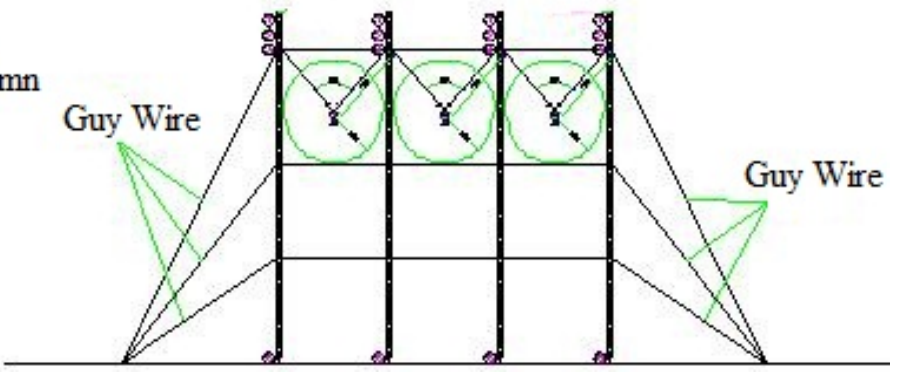

Fig.1 Schematic Diagram of the Repair Tower

\section{Structure Design and Optimization}

Overall Stability and Structural Arrangement Optimization.Relations between the overall stability of the column and the structural arrangements are: 1 . the interval of guy wires, namely the height of the column between guy wires; 2 . column width. Through calculation, it is drawn that the overall stability of the column can be effectively increased by reducing guy wire interval and increasing column width. With consideration of difficulty of construction and economic factors, the number of arrangement layers of guy wires should be reasonably selected, and the column width can not indefinitely increased. Therefore, an optimization process is conducted by this paper, in which the overall stability is regarded as the objective function, and number of arrangement layers of guy wires and width of the column are regarded as variables, and unit weight of the standard segment and total weight of the column are regarded as the control boundary. The initial variable will take an empirical value: single layer of guy wires, column width of $0.8 \mathrm{~m}$. The optimization process of a montanic tangent tower is shown in Table.1.

Table.1 Optimization Process of Structural Arrangement of the Montanic Tangent Tower

\begin{tabular}{|c|c|c|c|c|c|c|}
\hline $\begin{array}{c}\text { Optimization } \\
\text { Procedure }\end{array}$ & $\begin{array}{c}\text { Number of } \\
\text { Guy Wire } \\
\text { Layers }\end{array}$ & $\begin{array}{c}\text { Column } \\
\text { Height(m) }\end{array}$ & $\begin{array}{c}\text { Column } \\
\text { Width[m] }\end{array}$ & $\begin{array}{c}\text { Main Material } \\
\text { Dimension }\end{array}$ & $\begin{array}{c}\text { Weight of } \\
\text { the Standard } \\
\text { Section[kg] }\end{array}$ & Overall Stability \\
\hline Initial & 2 & 30 & 0.8 & Unable to Select & $/$ & Overall Stablilty Control \\
\hline The First Time & 2 & 30 & 1 & $200 X 24$ & 555 & Overall Stablility Control \\
\hline The Second Time & 2 & 30 & 1.2 & $140 X 14$ & 479 & Single Column Stability Control \\
\hline The Third Time & 3 & 21 & 1 & $140 X 16$ & 264 & $\begin{array}{c}\text { Simultaneous Control of the } \\
\text { Overall Stablility and Single } \\
\text { Column Stability, i.e. the Optimal } \\
\text { Allocation }\end{array}$ \\
\hline
\end{tabular}

The above table shows that in the third optimanization process, when both overall stability and single column stability of the main material are achieved by a reasonable selection of guy wire interval and column width, the weight of the standard section is $52.4 \%$ less than that obtained in the first optimanization process.

Optimalization of the Arrangement Form of Diagonal Members. The main column of the repair tower is the major component of load bearing, thus the selection of its main material should be controlled by the stability bearing capacity of each member. According to the calculation method of an aluminum alloy described above, the stability bearing capacity of each member is similar to that of angle steel, and it is related to the calculation length of members and the constraining conditions of their two ends. And these two aspects are determined by the arrangement form of diagonal members. To make the utilization rate of main material bearing capacity reasonable and to reduce the weight of the tower by controlling specifications of diagonal members and transvers 
members, it is necessary to study arrangement forms of diagonal members and optimize corresponding aspects.

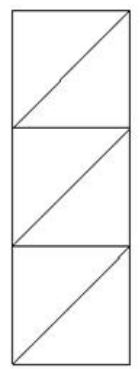

(a)

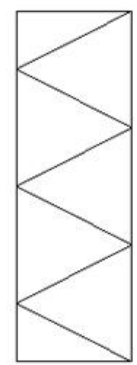

(b)

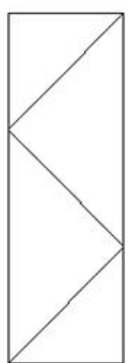

(c)

Fig.2 Arrangment Forms of Different Types of Diagonal Members

In Fig.2, it lists the scheme of arrangement forms of several standard sections. $a$ is the arrangement form of diagonal members whose stability bearing capacity is calculated by the smallest axis of 1meter, $b$ is the arrangement form of diagonal members whose stability bearing capacity is calculated by the parallel axis of 1meter, and $c$ is the arrangement form of diagonal members whose stability bearing capacity is calculated by the parallel axis of 2 meters. The tower of the largest load in this project, i.e. the montanic strain tower of the second type will be used as an example for trial calculatiom. The results of trial calculation are listed in Table 2.

Table 2 Calculation Results of the Montanic Strain Tower of the Second Type

\begin{tabular}{|c|c|c|c|c|c|c|}
\hline $\begin{array}{c}\text { Arrangment of } \\
\text { Diagonal Members }\end{array}$ & $\begin{array}{c}\text { Weight of Standard } \\
\text { Section[t] }\end{array}$ & $\begin{array}{c}\text { The Guy } \\
\text { Wire }\end{array}$ & $\begin{array}{c}\text { Main } \\
\text { Specification }\end{array}$ & Stress Ratio & $\begin{array}{c}\text { Type of } \\
\text { Stability Control }\end{array}$ & $\begin{array}{c}\text { Control } \\
\text { Conditions }\end{array}$ \\
\hline $\begin{array}{c}\text { The Smallest Axis of 1 } \\
\mathrm{m}\end{array}$ & 0.485 & $\begin{array}{c}\text { Two } \\
\text { Layers }\end{array}$ & $200 \times 18$ & $91.20 \%$ & $\begin{array}{c}\text { Single Column } \\
\text { Stability }\end{array}$ & $90^{\circ}$ Wind \\
\hline $\begin{array}{c}\text { The Parallel Axis of } \\
\text { 1m }\end{array}$ & 0.435 & $\begin{array}{c}\text { Two } \\
\text { Layers }\end{array}$ & $180 \times 18$ & $89.40 \%$ & $\begin{array}{c}\text { Single Column } \\
\text { Stability }\end{array}$ & $90^{\circ}$ Wind \\
\hline $\begin{array}{c}\text { The Parallel Axis of 2 } \\
\mathrm{m}\end{array}$ & 0.555 & $\begin{array}{c}\text { Two } \\
\text { Layers }\end{array}$ & $200 \times 24$ & $74.70 \%$ & $\begin{array}{c}\text { Single Column } \\
\text { Stability }\end{array}$ & $90^{\circ}$ Wind \\
\hline
\end{tabular}

It can be seen from the table that the specification of the main material which adopts the arrangement form of 1 meter parallel axis is smaller than that of the main material which adopts the initial arrangement form of the smallest axis of 1meter, and the weight of the standard section decreases about $10 \%$.

\section{Economic Analysis of the Material}

In order to further reduce the weight, and for easy transportation and installation, high-strength aluminum alloy and conventional angle steel are modeled, calculated and analyzed by this paper, and the optimal component materials are determined. The comparison of their weight of Q420 and 7A04 are shown in Table 3.

Table 3 Weight Comparison of 1000kV Tangent Tower Q420 and 7A04 T6 Aluminum

\begin{tabular}{|c|c|c|c|c|c|}
\hline \multirow[b]{2}{*}{$\begin{array}{c}\text { Total Tower Heigh } \\
{[\mathrm{M}]}\end{array}$} & \multicolumn{2}{|c|}{ Q420 } & \multicolumn{2}{|c|}{$7 \mathrm{a} 04$} & \multirow[b]{2}{*}{$\begin{array}{c}\text { (Aluminum - } \\
\text { Steel) / Steel [\%] }\end{array}$} \\
\hline & $\begin{array}{c}\text { Standard Segment } \\
\text { Weight [Kg] }\end{array}$ & $\begin{array}{c}\text { Full Tower Weight } \\
{[\mathrm{Kg}]}\end{array}$ & $\begin{array}{c}\text { Standard Segment } \\
\text { Weight }[\mathrm{Kg}]\end{array}$ & $\begin{array}{c}\begin{array}{c}\text { Full Tower Weight } \\
{[\mathrm{Kg}]}\end{array} \\
\end{array}$ & \\
\hline 67 & 352.2 & 30994 & 192.3 & 16922 & 45.40 \\
\hline
\end{tabular}

According to the calculation results, the specification and the internal forces of the main diagonal member which adopts angle steel are both smaller than that of diagonal member, which adopts steel aluminum. However, the weight of the main material in case of using angle steel is bigger than that of aluminum. In other words, to shorten time for transportation and installation, the lighter and stronger 7A04 angle aluminum should be employed as the repair tower material. 


\section{Summary}

On the basis of design conditions, including terrain conditions and load conditions, this paper designed a rush-repair tower made of aluminum for the $1000 \mathrm{kV}$ UHV transmission lines. Findings and conclusions of this paper are as follow:

(1)It designed a special modular rush-repair tower and pole structure for $1000 \mathrm{kV}$ transmission line tower;

(2)It carried out an optimizing design of the structure of the rush-repair tower;

(3)The trial calculation results show that the weight of the tower made by new aluminum material 7A04-T6 is $45.40 \%$ lighter than that made of Q420.

\section{Acknowledgements}

This work was financially supported by the State Grid Corporation of China Science and Technology Foundation (GC71-13-041).

\section{References}

[1] Mechanical Design Manual [M]. Beijing: Mechanical Industry Publishing House, 1991.

[2] Cheng Yingtang. Design, installation, Test and Application of Hardwares of the Transmission Line [M]. Beijing: Water Conservancy and Electric Power Press, 1989.

[4] Manual of the Electric Power Fittings, Dong Ji’e, China Electric Power Press

[5] The Ultra-High Voltage Grid, Liu Zhenya (Ed.), China Economic Publishing House

[6] Electrical Power Engineering High-Voltage Transmission Line Design, Zhang Diansheng (Ed.), China Electric Power Press

[7] The Power Industry Standards of People’s Republic of China. Technical Regulations of Design for Tower and Pole Structures of Overhead Transmission Line(DL/T 5154-2012)[S]. 2012. 